\title{
Enhancing impact: visualization of an integrated impact assessment strategy
}

Gary R. Krieger ${ }^{1}$, Michel A. Bouchard ${ }^{2}$, Isabel Marques de Sa ${ }^{3}$, Isabelle Paris ${ }^{3}, Z_{\text {Zachary Balge }}^{1}$, Dane Williams ${ }^{4}$, Burton H. Singer ${ }^{5}$, Mirko S. Winkler ${ }^{6,7}$, Jürg Utzinger ${ }^{6,7}$

${ }^{1}$ NewFields, LLC, Denver, CO 80202, USA; ${ }^{2}$ McGill-UNEP Collaborating Centre on Environmental Assessment, Montreal, QC H9X 3V9, Canada; ${ }^{3}$ International Finance Corporation, Washington DC 20433, USA; ${ }^{4}$ NewFields, LLC, Sacramento, CA 95811, USA; ${ }^{5}$ Emerging Pathogens Institute, University of Florida, Gainesville, FL 32610, USA; ${ }^{6}$ Department of Epidemiology and Public Health, Swiss Tropical and Public Health Institute, P.O. Box, CH-4002 Basel, Switzerland; ${ }^{7}$ University of Basel, P.O. Box, CH-4003 Basel, Switzerland

\begin{abstract}
The environmental impact assessment process is over 40 years old and has dramatically expanded. Topics, such as social, health and human rights impact are now included. The main body of an impact analysis is generally hundreds of pages long and supported by countless technical appendices. For large, oil/gas, mining and water resources projects both the volume and technical sophistication of the reports has far exceeded the processing ability of host communities. Instead of informing and empowering, the reports are abstruse and overwhelming. Reinvention is required. The development of a visual integrated impact assessment strategy that utilizes remote sensing and spatial analyses is described.
\end{abstract}

Keywords: extractive industry, impact assessment, remote sensing, spatio-temporal visualization.

Link: https://www.youtube.com/watch?v=F738OFeyubQ\&spfreload=10

\section{Background}

In December 1969, the National Environmental Policy Act (NEPA) was endorsed by law in the United States of America (USA), which triggered the development of formal environmental impact statements (EIS) (NEPA, 1970). The US Council on Environmental Quality (CEQ) considers NEPA as the "Magna Carta of environmental laws" (CEQ, 2007). As the EIS process developed, the CEQ established a target size for EIS as "normally not to exceed 150 pages in length and for proposals of unusual scope or complexity 300 pages" (CEQ, 2002). The English translation of the original Magna Carta is less than 5,000 words in total length, while current environmental, social and health impact statements often need thousands of pages, with 10-30 volumes of supporting appendices. For example, the mid-1990s Chad-Cameroon petroleum development and pipeline project EIS contained tens of thousands of pages spanning 21 volumes (Utzinger et al., 2005).

\footnotetext{
Corresponding author:

Gary R. Krieger

NewFields, LLC

Denver, CO 80202, USA

Tel. +1 303294 0950; Fax +1 3032949220

E-mail: gkrieger@newfields.com
}

Although produced with the best of intentions towards the impacted communities and other key stakeholders, one wonders if anyone can possibly read all of this kind of material. Can indeed anybody in a potentially impacted community possibly understand the highly technical nature of the analyses presented? Our group has reviewed and/or contributed to numerous extractive industry and water resources impact assessments (IAs) in developing countries (Utzinger et al., 2005; Krieger et al., 2008, 2010; Winkler et al., 2011, 2012a). Without exception, these IAs, including our own health impact assessments (HIA), are elaborate, multi-volume documents, all certainly reach a "magna" length. However, at issue is whether they are actually serving a useful purpose for potentially impacted communities.

We conjecture that these reports are hardly read by anyone, let alone fully appreciated, thereby leading to much less long-term follow-up and mitigation than might otherwise be the case. The lack of impact of IAs - on corporate management, governments and financial institutions - has motivated the introduction of short video reports as the output to be placed in front of all parties to a development project. The current paper products would then serve as appendices to provide much greater detail to peers who might be implementing mitigation strategies mandated by upper-level 
management who can readily react to video output but who have - heretofore - been only minimally engaged with the full set of IAs (Box 1).

\section{Visual display of quantitative information}

Motivated by a series of books put forth by Edward R. Tufte (Tufte, 1990, 2006) on how to envision and visually display quantitative information so that the maximum of information is conveyed in the simplest and most visual manner, our group has been developing and creating a series of "visualizations" for IA projects (Winkler et al., 2012b). These visualizations emphasize spatial reasoning and relationships for various stakeholders and project proponents. The visualizations are primarily focused on health impacts, but we have also developed similar materials for integrated environmental and social IAs based on specific criteria:

(i) visualizations should be between 5 and $15 \mathrm{~min}$ utes in length;

(ii) spatial relationships and connections should be emphasized;

(iii) graphs, photos, animation, satellite imagery and data used in the presentation should meet the highest scientific standards and be readily accessible in the full length IA;

(iv) visualization can be created using commercially available software tools;

(v) geospatial data and imagery (e.g. high-resolution satellite captures) would be, where appropriate, an underlying structural framework for the presentation;

(vi) geographical information systems (GIS) analysis could, where appropriate, be a critical analytic and presentation platform that would be part of the presentation architecture;

(vii) a voice-over using local languages and speakers could be utilized;

(viii) an English language version including detailed script should be created;

(ix) different versions could be generated for specific target audiences;

(x) the visualization should be compressed so that it can be readily watched on a project website;

(xi) the visualization should preferably be available in a variety of file formats so that that it can be presented on laptops, iPads or dedicated display projectors; and

(xii) the visualization could be presented using handheld battery operated pico projectors, so that the presentation can be shown in communities that lacked electricity.
We have created specific visualizations for mining, oil/gas and water resources projects using this set of criteria. In addition to this kind of visualization, we have also developed a series of printed "supergraphic" handouts that capture a set of key presentation images and spatial relationships. The "supergraphic" is a concept developed by Tufte (http://www.edwardtufte.com /tufte/posters) based on Charles J. Minard's graphic chart of Napoleon's 1812 Russian campaign showing the number of surviving men in the French "Grand Armée” at various intervals (Minard, 1869).

For the current vHealth paper, we present a visual environmental, social and health impact assessment (ESHIA) of a proposed mining project in Tajikistan. This work was prepared for the International Finance Corporation (IFC), a member of the World Bank Group that acts as advisor to the Government of Tajikistan for the mobilization of private sector participation in the development of a large silver/base metal mine.

Box 1. Purpose of the visualization.

- Visual analytic tool for synthesizing and integrating environmental, social and health information.

- Educational tool for facilitating proponent and stakeholder engagement.

- Critical environmental, social and health aspects are covered, including potential resettlement of the target local community.

- Demonstration of a variety of remote sensing and spatial techniques, including an example of object-based imagery analysis.

- Demonstration of how high-resolution satellite imagery can be readily integrated into the visual narrative.

- Demonstration of geo-coding and rectifying all ground level photos to the satellite imagery so that photographic visuals are accurately integrated into all of the satellite based maps.

Box 2. Applied software.

- Satellite imagery pre-processing, including format conversion, projection transformation, ratio and transformation calculations (ERDAS IMAGINE 2011, version 11.04; Integraph Corporation; Huntsville, AL, USA).

- GIS compilation, entity attribution, geometry corrections, format conversion, geoprocessing calculations, relational database calculations (ArcGIS version 10.0; ESRI Inc.; Redlands, CA, USA).

- Object-based imagery analysis, imagery segmentation, land feature classification (eCognition version 8.7.1; Trimble Germany GmbH; Munich, Germany).

- Three-dimensional fly-through visuals and video sequence generation, overlay of project-specific satellite imagery and GIS products (Google Earth Pro version 6.2.1; Google, Inc.; Mountain View, CA, USA).

- Graphic design, video formatting and effects (Adobe Creative Suite 5.5; Adobe System Incorporated; San Jose, CA, USA). 


\section{Case study}

An overall "scoping study" of the key environmental, social and health issues associated with the proposed mine was performed by two of the current authors (GRK and MAB). The study was a rapid assessment, time- and resource-limited, ring-fence ${ }^{1}$ effort and was not intended to be a comprehensive study. The objectives of the scoping study were to:

(i) identify the scale and the extent of contamination;

(ii) evaluate the contamination boundaries - so that bidders could "ring-fence" Government of Tajikistan liabilities;

(iii) define the scope of work (preliminary terms of reference and cost estimates) for the full detailed baseline study to be carried out to as part of any future ESHIA project; and

(iv) present potential mitigation measures and cost estimates for any contamination that will have to be remediated or other measures undertaken (e.g. tailings dam stabilization) prior to the start of the new mine development.

In addition to the visualization, a technical report was prepared as an appendix. The target audiences for the visualization were IFC financial advisory specialists, IFC IA specialists and Government of Tajikistan officials. Both English and Russian language versions were created.

The presentation connects and integrates the crosscutting environmental, social and health issues so that a viewer can readily grasp the size and depth of potential impacts to the host community. The receptivity with respect to the visual ESHIA was positive and senior financial advisors emphasized that they preferred this way of rapidly gathering key information rather than wading through $40+$ pages of highly technical and specialized multimedia scientific data. Indeed, the visual ESHIA does allow for an immediate grasp of the magnitude and extent of potential contamination, resettlement issues and potential positive and negative health impacts.

The preparation of the Tajikistan visual required detailed analysis and the technical input of sophisticated remote sensing and spatial analysis specialists in order to process and present the geospatial data and imagery. The creation of the visualization is not a trivial technical exercise. Instead, it is designed to allow the viewer to (i) see important spatial relationships

\footnotetext{
${ }^{1}$ business term used to identify critical risk factors regarding environment, social and health liabilities that would accrue if a project moved forward.
}

and connections, and (ii) facilitate critical visual thinking and analysis.

\section{Outlook}

The visual ESHIA may not replace the multi-volume IAs but it can capture the analyses in a way that can be understood and processed by a broader range of proponents and stakeholders. Visualization can inform and empower in a way that hundreds of pages cannot. We believe that the traditional IA presentation and information transmission process requires a complete re-envisioning and reworking. Project proponents and stakeholders need a new method to both understand and process the voluminous materials that are being created on their behalf. The reception to our visualizations has been overwhelmingly positive. We invite the IA communities to build upon these first examples.

\section{Acknowledgements}

The authors acknowledge the contribution and support of the IFC.

\section{References}

CEQ, 2002. U.S. Code of Federal Regulations: title 40 Protection of environment. Environmental impact statement 1502.7: page limits. Washington, DC, US: Executive Office of the President of the United States.

CEQ, 2007. A citizen's guide to the NEPA: having your voice heard. Washington, DC, US: Executive Office ot the President of the United States.

Krieger GR, Balge MZ, Chanthaphone S, Tanner M, Singer BH, Fewtrell L, Kaul S, Sananikhom P, Odermatt P, Utzinger J, 2008. Nam Theum 2 hydroelectric project, Lao PDR. In: Fewtrell L, Kay D, editors. Health impact assessment for sustainable water management. London, UK: IWA Publishing pp. 199-232.

Krieger GR, Utzinger J, Winkler MS, Divall MJ, Phillips SD, Balge MZ, Singer BH, 2010. Barbarians at the gate: storming the Gothenburg consensus. Lancet 375, 2129-2131.

Minard CJ, 1869. Chart showing the losses in men, their movements, and the temperature of Napoleon's 1812 Russian campaign.

NEPA, 1970. National environmental policy act of 1969. Washington, DC, US: U.S. Environmental Protection Agency. Tufte ER, 1990. Envisioning information. Cheshire, Connecticut, US: Graphics Press.

Tufte ER, 2006. Beautiful evidence. Cheshire, Connecticut, US: Graphics Press.

Utzinger J, Wyss K, Moto DD, Yemadji N, Tanner M, Singer 
BH, 2005. Assessing health impacts of the Chad-Cameroon petroleum development and pipeline project: challenges and a way forward. Environ Impact Assess Rev 25, 63-93.

Winkler MS, Divall MJ, Krieger GR, Balge MZ, Singer BH, Utzinger J, 2011. Assessing health impacts in complex eco-epidemiological settings in the humid tropics: the centrality of scoping. Environ Impact Assess Rev 31, 310-319.

Winkler MS, Divall MJ, Krieger GR, Schmidlin S, Magassouba
ML, Knoblauch AM, Singer BH, Utzinger J, 2012a. Assessing health impacts in complex eco-epidemiological settings in the humid tropics: modular baseline health surveys. Environ Impact Assess Rev 33, 15-22.

Winkler MS, Krieger GR, Divall MJ, Singer BH, Utzinger J, 2012b. Health impact assessment of industrial development projects: a spatio-temporal visualization. Geospat Health 6, 299-301. 